Kalpa Publications in Civil Engineering
Volume 1, 2017, Pages 137-143
$\begin{gathered}\text { ICRISET2017. International Conference on Re- } \\ \text { search and Innovations in Science, Engineering } \\ \text { \&Technology. Selected papers in Civil Engineering }\end{gathered}$

\title{
Impact Resistance of Geopolymer Concrete Containing Recycled Plastic Aggregates
}

\author{
Shemal V. Dave ${ }^{1}$, Ankur C. Bhogayata ${ }^{2}$, Dr. N.K.Arora ${ }^{3}$ \\ ${ }^{1}$ Assistant Professor, Civil Engineering department, Marwadi Education Foundation's Group of \\ Institutions, Rajkot, Gujarat, India \\ ${ }^{2}$ Associate Professor and head, Civil Engineering department, Marwadi Education Foundation's \\ Group of Institutions, Rajkot, Gujarat, India \\ ${ }^{3}$ Principle, Lakhdhirji Engineering College, Morbi, Gujarat, India \\ shemal2203@gmail.com, ankur.bhogayata@gmail.com, \\ narendrakarora@gmail.com
}

\begin{abstract}
This paper represents test results of impact resistance of geopolymer concrete (GPC) containing recycled plastic aggregates (RPA). Natural fine aggregates of $10 \mathrm{~mm}$ size were partially replaced by RPA in varying proportions. Impact resistant offered by GPC was obtained by performing drop hammer test conforming to suggestions by ACI 544.2R-89. The test results revealed excellent improvement of impact resistance and energy absorption at $10 \%$ replacement of natural aggregates by RPA. The experimental evaluation of GPC modified by RPA, demonstrated potential for novel usage of waste plastic with GPC towards the development of sustainable construction material.
\end{abstract}

\section{Introduction}

Plastic is one of the most consumptive materials all over the world. In the 19th century as chemical industries developed with industrial revolution gave boost to plastic production and consumption. Plastic is a difficult material to get rid of due to its excellent sustainable properties. Today tons of plastic is floating all over the globe as a waste material, which is proving hazardous to the environments [1].Management and safe disposal of plastic waste has become a compulsion to keep the environment clean and healthy. Utilization of plastic waste as construction material may be one of the solutions towards green and healthy environment [2].

Cementitious concrete is one of the energy intensive materials being the second major source of generation of carbon dioxide after automobile and needs an attention to get an alternative. Geopolymer concrete prepared with industrial wastes namely fly ash and alkaline activator has emerged as one such alternative to the cement based concrete in recent decades. After being first 
coined by Prof. Glukhovsky in the former Soviet Union in the middle of 20th century, later in 1970s Prof. J. Davidovits [3-5] researched on a chemistry of geopolymer binder and its application as a construction material. Usage of pozzolanic materials viz. fly ash, red mud and alkaline activators makes GPC an environment friendly and less energy intensive construction material.

As an extension of sustainable construction materials preparation, addition of waste plastic is utilized as recycled plastic aggregates (RPA) with the conventional constituents of GPC in the present study.

Noticeable work is been carried out by many researchers on the usage of waste plastic in concrete as well as in GPC. A. Bhogayata et. \& all [6] tested the concrete blended with recycled plastic and had a thickness of less than 20micron.Reduction in strength up to certain extent was observed. However, it was still a bearable way of disposal of plastic. Physical and mechanical behavior was tested for waste PET bottle fibres used in conventional concrete by Luiz A. Pereira de Oliveira \& João P. CastroGomes [7]. Zainab Z. Ismail and their fellow colleagues [8] used waste plastic in concrete mixture as aggregate replacement; it has mentioned that, the compressive strength values of all specimen containing waste plastic likely to decrease below the values for the reference specimen, with increasing the amount of waste plastic at all curing periods. This may be characterized to the decrease in the adhesive bonding between the plastic waste surface $\&$ cement paste. In addition, waste plastic is hydrophobic material, which may restrict the hydration process of cement. R. A. Patel, Ankur Bhogayata and their fellows [9] worked on Flexural response of Geopolymer concrete beam containing metalized plastic waste, the beam was analyzed using stress strain behavior, it is highlighted that, for analytical study moment resistance capacity was decreased $12.92 \%, 4.54 \%$ and $3.72 \%$ in shear reinforced beam, over reinforced beam and under reinforced beam respectively as compare to experimental.

The objective of this experimental study deals with the effects of addition of RPA in GPC by various proportions and to check the possibilities to utilize hazardous plastic waste as a construction material and come up with solution for the environmental pollution issues rose due to the increasing plastic waste disposal. For this experimental investigation, plastic waste that might have no potential application or utilization was collected from local plastic industries nearby the Rajkot city. Road side plastic waste melted to form lumps and grinded in to $10 \mathrm{~mm}$ average sized particles can be utilize as a constituent of concrete as a partial replacement of grit [12-13]. Fig.1shows plastic waste reformed in to PRA collected from plastic pipe manufacturing industries.

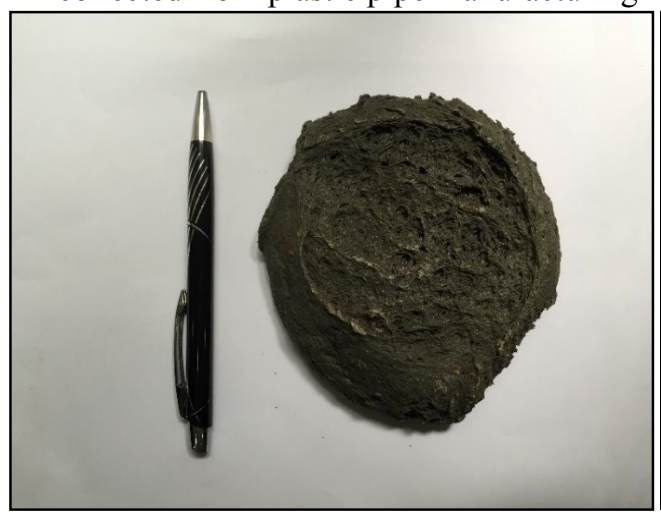

(a) A LUMP OF RECYCLED PLASTIC

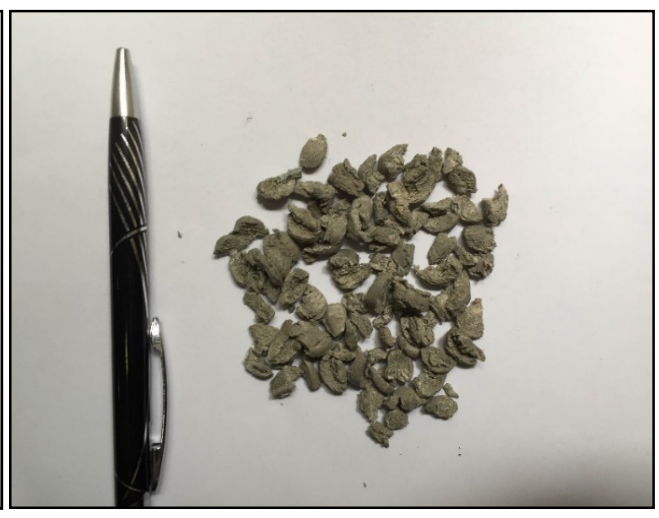

(b) GRINDED LUMP IN TO RPA

Figure 1: PRA PREPARATION 


\section{Document Header}

Recycled plastic waste was mixed as a replacement of $10 \mathrm{~mm}$ aggregate, concrete mix was prepared using low calcium, Class F fly ash (ASTM-C618) obtained from the Wanakbori Thermal Power Station, Gujarat, India, as it is much preferred in making of GPC due to the high content of amorphous alumino silicate phases and greater workability. Specific gravity of Fly ash used was 2.4. The chemical composition of Fly ash was obtained by X-ray fluorescence test as mentioned in Table 2. RPA was added as a partial replacement of $10 \mathrm{~mm}$ aggregate in variation of $0 \%, 5 \%, 10 \%$, and $15 \%$ by weight of natural aggregates. Physical properties of RPA are mentioned in Table 1. A combination of sodium silicate $(\mathrm{Na} 2 \mathrm{SiO} 3)$ solution and sodium hydroxide $(\mathrm{NaOH})$ solution was used as the alkaline binder. It is proposed that the alkaline binder need to be rendered by combining both of the solutions together at least one day advance to use. The solids was dissolved in water to make a solution with the required concentration. The concentration of sodium hydroxide solution can vary in from 8 to 16 molar. The mass of $\mathrm{NaOH}$ solids in a solution varies depending on the concentration of the solution; for example, $\mathrm{NaOH}$ solution with a concentration of 16 molar consists of $16 \times 40=640$ $\mathrm{g}$ of $\mathrm{NaOH}$ solids per liter of the solution, where 40 is the molecular weight of $\mathrm{NaOH}$. It was observed that mechanical strength of Geopolymer concrete is depends upon Molarity of the alkaline solution: Higher the molar content, higher the strength. For this experimental work 16 Molar solutions was used. Concrete mix was then placed in a mould and vibrated on a table vibrator in order to remove residue and air bubbles. All specimens were cured undisturbed for $24 \mathrm{hr}$ at $100^{\circ} \mathrm{C}$ in oven. At the end of the curing system, the specimens were carefully expel from their casting molds and allowed to cure at room temperature before primary physical properties were tested. Table shows mix proportion that was used to cast concrete specimen. Hardened mass then tested for impact resistance as per the standard mentioned in ACI 544.2R-89. Styles

\begin{tabular}{ll}
\hline Properties & $\begin{array}{l}\text { Plastic } \\
\text { granules }\end{array}$ \\
\hline Specific gravity & 0.7 \\
Water absorption & $<0.3$ \\
Colour & Grey \\
Shape & Irregular \\
Surface & Rough \\
Size & $7-9 \mathrm{~mm}$ \\
Properties & Plastic \\
& granules \\
\hline
\end{tabular}

Table 1: PHYSICAL PROPERTIES OF PLASTIC WASTE

\begin{tabular}{ll}
\hline Oxide & Percentage (\%) \\
\hline Silica (SiO2) & 50 \\
Alumina (A12O3) & 28 \\
Ferric Oxide (Fe2O3) & 12 \\
Calcium Oxide (CaO) & 6.5 \\
Magnesium Oxide (MgO) & 06 \\
Potassium Oxide(K2O) & 1.5 \\
Sodium Oxide (Na2O) & 0.2 \\
\hline
\end{tabular}

Table 2: CHEMICAL COMPOSITION OF FLYASH BY XRF TEST 


\begin{tabular}{lll}
\hline Constituent & Value & Unit \\
\hline Fly Ash & 368 & $\mathrm{~kg} / \mathrm{m} 3$ \\
Sand & 554.4 & $\mathrm{~kg} / \mathrm{m} 3$ \\
Coarse Aggregate & & \\
$10 \mathrm{~mm}$ & 443.52 & $\mathrm{~kg} / \mathrm{m} 3$ \\
$20 \mathrm{~mm}$ & 850.08 & $\mathrm{~kg} / \mathrm{m} 3$ \\
$\mathrm{NaOH}$ solution & 46 & $\mathrm{~kg} / \mathrm{m} 3$ \\
$\mathrm{Na} 2 \mathrm{sio} 3$ & 138 & $\mathrm{~kg} / \mathrm{m} 3$ \\
Extra water & 29.44 & $\mathrm{~kg} / \mathrm{m} 3$ \\
NaOH Molarity & 16 & Molar \\
Curing Time & 24 & hours \\
Curing Temperature & $100^{\circ}$ & Celsius \\
Type of curing & Oven Curing &
\end{tabular}

Table 3: CHEMICAL COMPOSITION OF FLYASH BY XRF TEST

\section{RESULTS AND DISCUSSION}

For this experimental work specimen was prepared as per the standard mention in ACI 544.2R-89. Circular specimen having height $=63.5 \mathrm{~mm}$ diameter $=100 \mathrm{~mm}$ was prepared. Dropping weight impact test was used to determine the impact resistance of a GPC. Test was conducted as per the standard mentioned in the ACI 544.2R-89. Figure 2 shows typical setup of a dropping weight impact strength assembly, Figure 2 shows undisturbed sample.

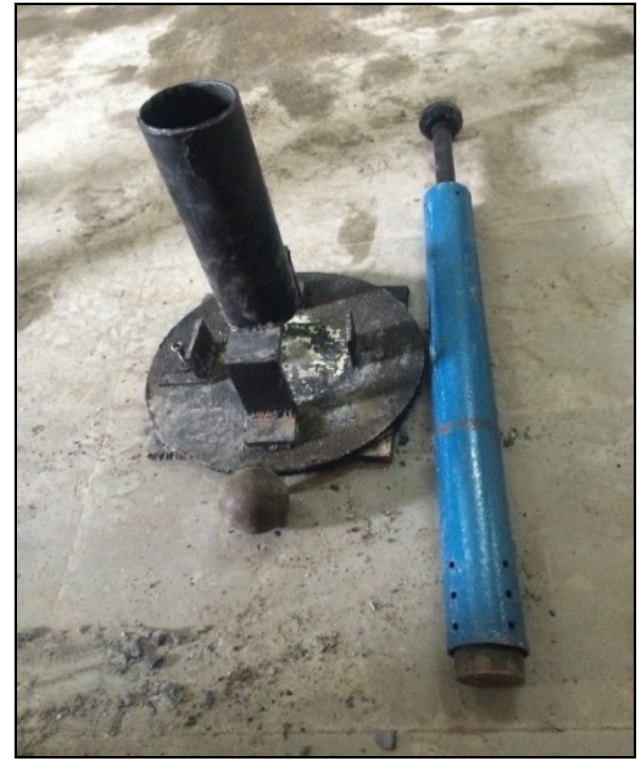

Figure 2: Drop weight impact apparatus

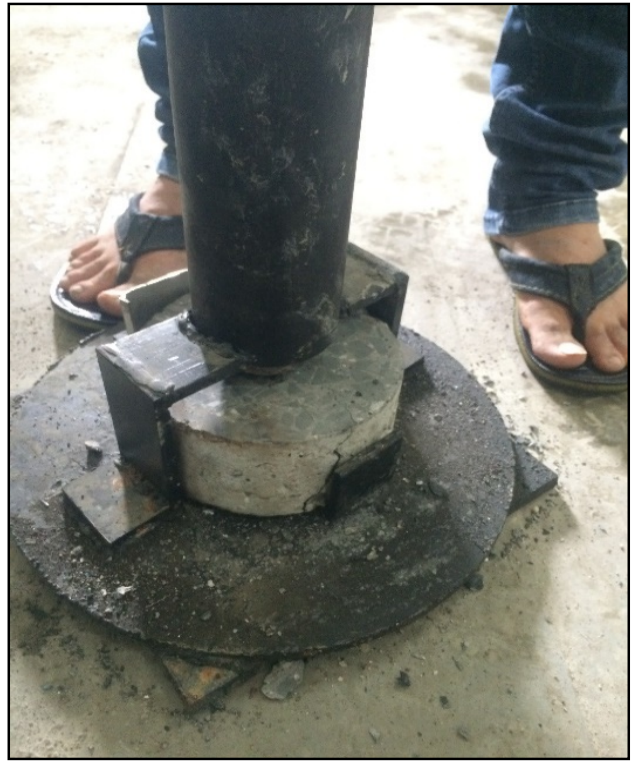

Figure 3 Testing of specimen under impact load 


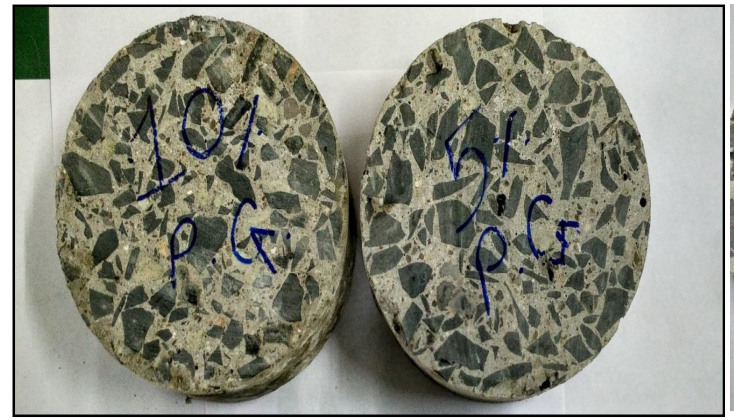

(a)

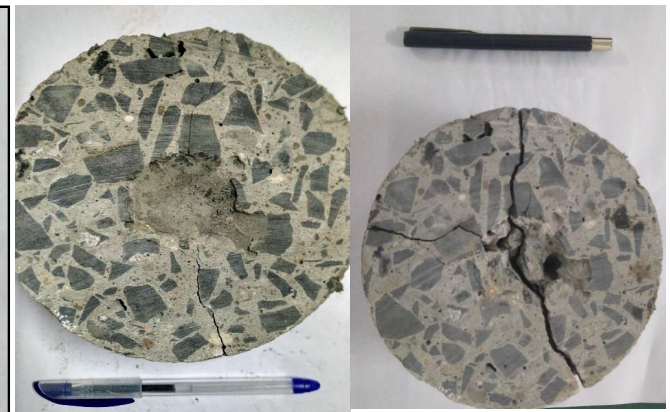

(b)

(C)

Figure 4 Specimen Detail (a) Disk Specimen (b) First visible crack (c) Final failure of specimen

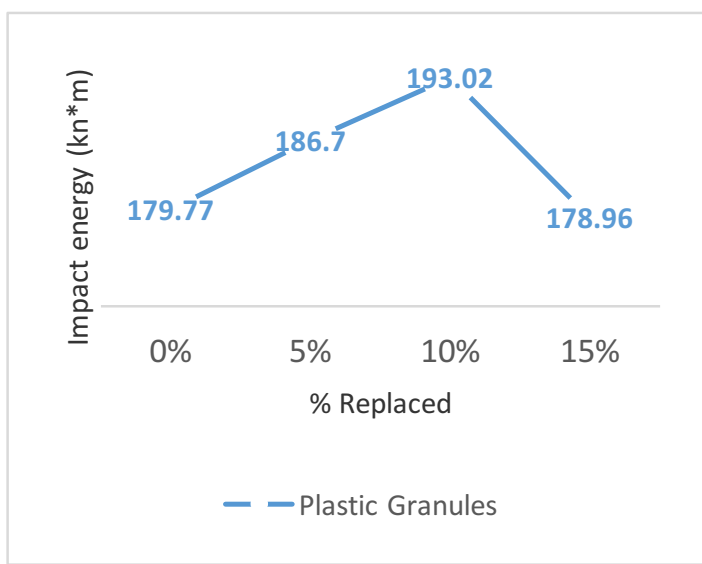

Figure 6: Results of drop weight impact resistance test

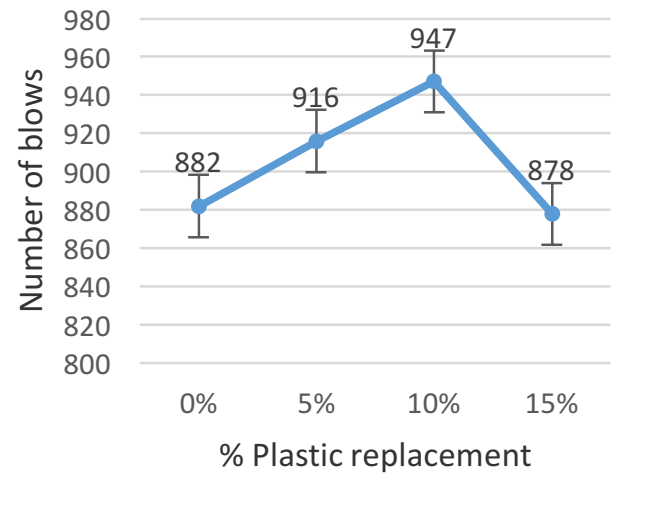

Figure 5: Relationship between blows and RPA

Impact energy of GPC containing plastic waste granules was observed $193 \mathrm{kN} * \mathrm{~m}$ along with 179.7 $\mathrm{kN}^{*} \mathrm{~m}$ of conventional GPC. Test results are shown in Figure 5. It was observed that inclusion of recycled plastic waste granules by $10 \%$ significantly increased impact energy of a hardened mass. Figure 6 represents number of blows required at complete failure of specimen.

After meticulous observation of broken sample, it was observed that after application of impact energy, plastic granules remain unchanged while natural aggregate chipped out. Figure 7 shows cross section of failed specimen, due to application of impact energy natural aggregate chipped out, while plastic granules remained undisturbed as plastic possess excellent ductile properties compare to natural aggregate, moreover plastic granules was successfully able to absorb sudden impact and inclusion of plastic resulted in changing the behavior of crack propagation as plastic was successfully able to arrest cracks at micro level hence it reduced gross crack propagation of hardened mass. 


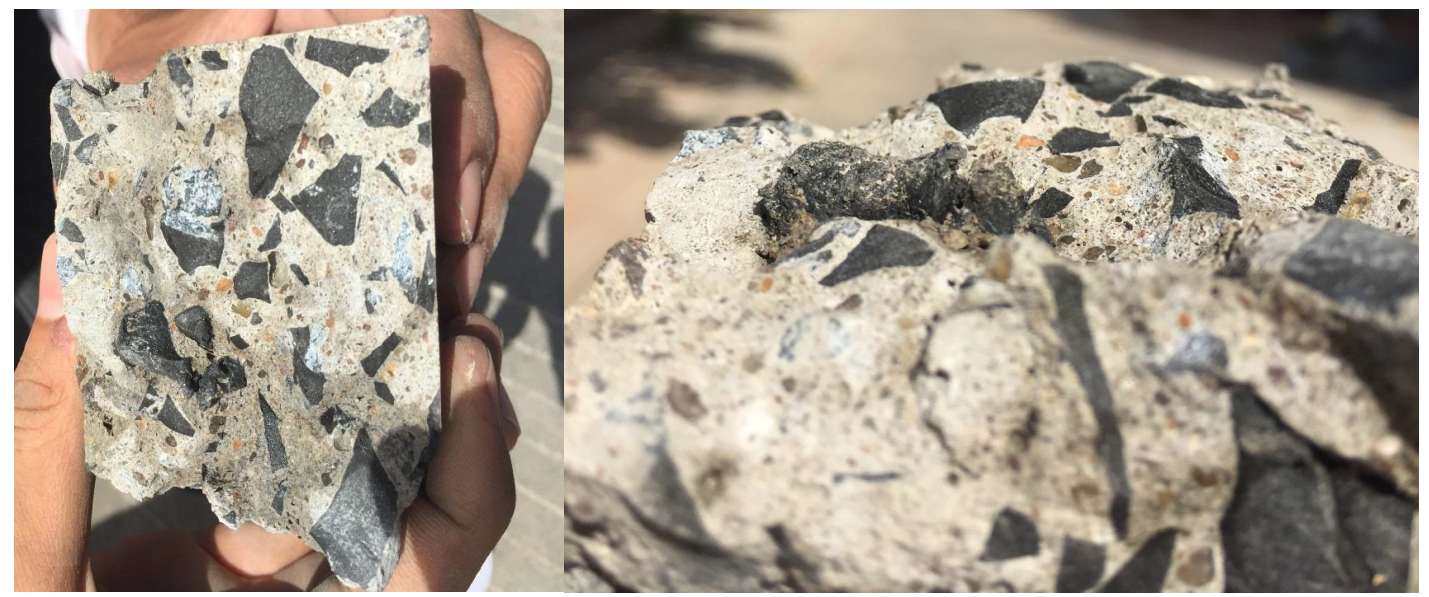

(a) Natural aggregate chipped out

(b) Plastic granules remain unchanged

Figure 7 Observation of broken sample.

\section{Conclusion:}

- The incorporation of plastic granules in GPC as replacement of $10 \mathrm{~mm}$ size natural aggregates by $10 \%$ by weight exhibited up to $10 \%$ improvement in drop weight impact strength.

- Presence of recycled plastic waste in concrete arrested cracks at micro level, which led to changing in gross crack formation pattern.

- Plastic waste that was incorporated, absorbed impact energy and remained unchanged, while natural aggregate failed to take impact energy and chipped out.

\section{References:}

[1] Andrady, Anthony L., and Mike A. Neal. "Applications and societal benefits of plastics." Philosophical Transactions of the Royal Society B: Biological Sciences 364.1526 (2009): 19771984.

[2] Sushant Agarwal, Rakesh K. Gupta, "Plastics in Buildings and Construction", Applied Plastics Engineering Handbook (Second Edition), Pages 635 - 649

[3] J. Davidovits, J. Therm. Anal, "Geopolymers and geopolymeric new materials". 35 (2) (1989) 429-441.

[4] J. Davidovits, M. Davidovits, Geopolymer: "ultrahigh-temperature tooling material for the manufacture of advanced composite", in: R. Adsit, F. Gordaninejad (Eds.), 36th Annual SAMPE Symposium and Exhibition, Covina, CA, USA, vol. 36, pt 2, 1991, pp. 1939-1949.

[5] J. Davidovits, Properties of geopolymer cements. Proceedings First International Conference on Alkaline Cements and Concretes, vol. 1, SRIBM, Kiev, Ukraine, 1994, pp. 131- 149.

[6] A. Bhogayata, K. D. Shah, and N. K. Arora. "Strength properties of concrete containing post consumer metalized plastic wastes." International Journal of Engineering Research and Technology. Vol. 2. No. 3 (March-2013). ESRSA Publications, 2013.

[7] de Oliveira, Luiz A. Pereira, and João P. Castro-Gomes. "Physical and mechanical behaviour of recycled PET fibre reinforced mortar." Construction and Building Materials 25.4 (2011): 17121717. 
[8] Ismail, Zainab Z., and Enas A. Al-Hashmi. "Use of waste plastic in concrete mixture as aggregate replacement." Waste Management 28.11 (2008): 2041-2047.

[9] Patel R. A., et al. "FLEXURAL RESPONSE OF GEOPOLOMER COCRETE BEAM CONTAINING METALLIZED PLASTIC WASTE." Int J Adv Engg Tech/IV/III/July-Sept 72 (2013): 74.

[10]. J. Davidovits, "Synthetic mineral polymer compound of the silicoaluminates family and preparation process". Patent US4472199, 1984.

[11] Kang, Hai-Yong, and Julie M. Schoenung. "Electronic waste recycling: A review of US infrastructure and technology options." Resources, Conservation and Recycling 45.4 (2005): 368400.

[12] S.V.Dave, A.C.Bhogayata, Dr.N.K.Arora "A Novel Experimental Study on Plastic Waste Utilization in Geopolymer Concrete", Concrete India, Journal of the India chapter of American Concrete Institute. October December 2015.

[13] S.V.Dave, A.C.Bhogayata, Dr.N.K.Arora "Experimental Study On Utilization Of Plastic Waste In Geopolymer Concrete", International Conference on ADVANCES IN CONCRETE TECHNOLOGY, MATERIALS \& CONSTRUCTION PRACTICES , 22-24 June 2016, Goa, India.

[14] Bakharev, T. "Resistance of geopolymer materials to acid attack." Cement and Concrete Research 35.4 (2005): 658-670.

[15] Bakharev, T. "Geopolymeric materials prepared using Class $F$ fly ash and elevated temperature curing." Cement and Concrete Research 35.6 (2005): 1224-1232.

[16] Miranda, J. M., et al. "Corrosion resistance in activated fly ash mortars." Cement and Concrete Research 35.6 (2005): 1210-1217.

[17] Bakharev, T. "Durability of geopolymer materials in sodium and magnesium sulfate solutions." Cement and Concrete Research 35.6 (2005): 1233-1246.

[18] Bakharev, Tatiana. "Thermal behaviour of geopolymers prepared using class $F$ fly ash and elevated temperature curing." Cement and Concrete Research 36.6 (2006): 1134-1147.

[19] Sofi, M., et al. "Engineering properties of inorganic polymer concretes (IPCs)." Cement and Concrete Research 37.2 (2007): 251-257. 